\title{
Article \\ Comprehensive Leaf Cell Wall Analysis Using Carbohydrate Microarrays Reveals Polysaccharide-Level Variation between Vitis Species with Differing Resistance to Downy Mildew
}

\author{
Yu Gao ${ }^{1} \mathbb{D}$, Xiangjing Yin ${ }^{2,3}$, Haoyu Jiang ${ }^{1}$, Jeanett Hansen ${ }^{4}$, Bodil Jørgensen ${ }^{4}$, John P. Moore ${ }^{5} \mathbb{D}$, Peining Fu ${ }^{1}$, \\ Wei $\mathrm{Wu}^{1}{ }^{1}$, Bohan Yang ${ }^{1}$, Wenxiu Ye ${ }^{1}$, Shiren Song ${ }^{1}$ and Jiang Lu ${ }^{1, *}$ \\ 1 Center for Viticulture and Enology, Department of Plant Science, School of Agriculture and Biology, \\ Shanghai Jiao Tong University, Shanghai 200240, China; yugao@sjtu.edu.cn (Y.G.); \\ jianghaoyu@sjtu.edu.cn (H.J.); fupeining@sjtu.edu.cn (P.F.); wuwei_hello@sjtu.edu.cn (W.W.); \\ ybh622@sjtu.edu.cn (B.Y.); yewenxiu@sjtu.edu.cn (W.Y.); sr.song@sjtu.edu.cn (S.S.) \\ 2 Forestry and Pomology Research Institute, Shanghai Academy of Agricultural Sciences, \\ Shanghai 201403, China; yinxiangjingsmile@163.com \\ 3 Shanghai Key Lab of Protected Horticultural Technology, Shanghai Academy of Agricultural Sciences, \\ Shanghai 201403, China \\ 4 Department of Plant and Environmental Sciences, Faculty of Sciences, University of Copenhagen, \\ 1871 Frederiksberg C, Denmark; jeha@plen.ku.dk (J.H.); boj@plen.ku.dk (B.J.) \\ check for \\ updates \\ Citation: Gao, Y.; Yin, X.; Jiang, H.; \\ 5 Department of Viticulture and Oenology, South African Grape and Wine Research Institute, \\ Stellenbosch University, Stellenbosch 7602, South Africa; moorejp@sun.ac.za \\ * Correspondence: Vitislab@sjtu.edu.cn
} Hansen, J.; Jørgensen, B.; Moore, J.P.; $\mathrm{Fu}$, P.; Wu, W.; Yang, B.; Ye, W.; et al. Comprehensive Leaf Cell Wall Analysis Using Carbohydrate Microarrays Reveals PolysaccharideLevel Variation between Vitis Species with Differing Resistance to Downy Mildew. Polymers 2021, 13, 1379. https://doi.org/10.3390/ polym13091379

Academic Editors: Emiliano Bedini and Serena Traboni

Received: 27 February 2021

Accepted: 21 April 2021

Published: 23 April 2021

Publisher's Note: MDPI stays neutral with regard to jurisdictional claims in published maps and institutional affiliations.

Copyright: () 2021 by the authors. Licensee MDPI, Basel, Switzerland. This article is an open access article distributed under the terms and conditions of the Creative Commons Attribution (CC BY) license (https:// creativecommons.org/licenses/by/ $4.0 /)$.
Abstract: The cell wall acts as one of the first barriers of the plant against various biotic stressors. Previous studies have shown that alterations in wall polysaccharides may influence crop disease resistance. In the grapevine family, several native species (e.g., Chinese wild grapevine) show a naturally higher resistance to microbial pathogens than cultivated species (e.g., Vitis vinifera), and this trait could be inherited through breeding. Despite the importance of the cell wall in plant immunity, there are currently no comprehensive cell wall profiles of grapevine leaves displaying differing resistance phenotypes, due to the complex nature of the cell wall and the limitations of analytical techniques available. In this study, the cutting-edge comprehensive carbohydrate microarray technology was applied to profile uninfected leaves of the susceptible cultivar (Vitis vinifera cv. "Cabernet Sauvignon"), a resistant cultivar (Vitis amurensis cv. "Shuanghong") and a hybrid offspring cross displaying moderate resistance. The microarray approach uses monoclonal antibodies, which recognize polysaccharides epitopes, and found that epitope abundances of highly esterified homogalacturonan (HG), xyloglucan (with XXXG motif), (galacto)(gluco)mannan and arabinogalactan protein (AGP) appeared to be positively correlated with the high resistance of Vitis amurensis cv. "Shuanghong" to mildew. The quantification work by gas chromatography did not reveal any significant differences for the monosaccharide constituents, suggesting that polysaccharide structural alterations may contribute more crucially to the resistance observed; this is again supported by the contact infrared spectroscopy of cell wall residues, revealing chemical functional group changes (e.g., esterification of pectin). The identification of certain wall polysaccharides that showed alterations could be further correlated with resistance to mildew. Data from the use of the hybrid material in this study have preliminarily suggested that these traits could be inherited and may be applied as potential structural biomarkers in future breeding work.

Keywords: cell wall; grapevine; oomycete; polysaccharide microarray; monoclonal antibodies

\section{Introduction}

The domesticated grapevine (Vitis vinifera) is susceptible to many pathogens, which may lead to huge losses in production. Unlike the vine trunk, which contains a higher per- 
centage of cellulosic and lignin components that are more recalcitrant to biological degradation, the grapevine leaves with a higher primary cell wall content are markedly more vulnerable to opportunistic pathogenic microorganisms, e.g., fungi [1]. Necrotrophic pathogens can secrete a wide range of cell wall-degrading enzymes (CWDEs) to effect almost the complete deconstruction of plant tissues [2]. In contrast to necrotrophs, which acquire nutrients from dead tissue, biotrophs need the host to be alive during infection/feeding and are found to implement "milder" penetration procedures [3]. Studies of biotrophs suggest that some of the enzymes employed can also be secreted from the haustoria of biotrophic pathogens interfacing with plants for more effective invasion; these may include a set of pectinases and hemicellulases depending on their targeted tissue types [4,5]. In contrast, plants have also evolved various defense mechanisms at the structural and molecular levels under different types of stresses [6]. These not only elevate their chances of survival and continuity, but they also act as selection pressures acting on the Vitis species during plant evolution. The biodiversity of the Vitis genus provides researchers with many valuable plant genetic resources for the investigation of molecular defense mechanisms against fungi, as well as contributing towards breeding programmes. Several studies have analyzed the differences between crops with close genetic relatedness from a cell wall structural perspective, and revealed compositional changes in polysaccharides and proteins, which are probably adaptive [4-9]. In addition to the cell wall compositional and structural differences observed, recent studies have also shown that the host plant is found to secrete inhibiting proteins that de-activate CWEDs as a means of protection [10-14]. These studies have broadened our views on the roles of the cell wall in plant-pathogen interactions. However, there are very few comparative studies from a cell wall structural point of view in grapevine-pathogen interactions, even though a variation in defense responses have been observed in the Vitaceae and genus Vitis [15].

Grapevine downy mildew is recognized as one of the more serious diseases to infect Vitis vinifera and is caused by the oomycete Plasmopara viticola. It is found to penetrate the grapevine leaves through stomata, and then develop haustoria on the hyphae to unravel the structure of the middle lamella and primary cell wall for nutrient uptake and later reproduction [16]. Microscopy studies have shown that a number of species in the Vitis genus could slow down the growth of hyphae in the leaf tissue; these include some Chinese native species (e.g., Vitis amurensis) and a number of American species [15,17,18]. To date, studies on the identification of resistance genes using QTL localisation and other molecular biological procedures have resulted in valuable progress [19-21]. Furthermore, studies from a phenotypical and physiological perspective have also provided useful information, in turn, aided by technology development. For instance, callose (beta-1,3-glucan) deposition was clearly observed near the tip end of hyphae of resistant grapevine species by using electron microscopy [15]. This clearly indicated that grapevine leaf cell walls could undergo localised structural alterations to adapt to external stresses, such as infection. However, it is regrettable that we still lack information on the comprehensive cell wall composition profiles of the grapevine leaves, as well as baseline compositional levels before pathogen infection between those Vitis species with differing resistance levels.

Far beyond providing the mechanical support of living cells, the plant cell wall acts as one of the first barriers in the frontline of plant-pathogen interactions [22]. It is widely recognized that the plant cell wall is among the most complex structures in nature, generally thought to consist of cellulose microfibrils embedded in a pectin and hemicellulose matrix [23]. However, the composition and conformation of these polysaccharide polymers are found to vary among the species, varieties and tissue types, as well as the developmental stages sampled [24]. These differences are necessary to ensure the functional processes linked to biological activities are performed effectively (e.g., fruit ripening, stem elongation and pollen tube formation) [24]. Furthermore, a number of previous research studies have indicated that some polysaccharide polymers can increase the rigidity and strength of the cell wall for protection [25-27]. However, the work on profiling technologies for the cell wall at the polysaccharide level was a challenge for many decades due to the limitations of 
the analytical techniques available. The recent development of carbohydrate microarray technology using monoclonal antibodies has overcome these issues and is able to generate high-resolution profiles of polysaccharide epitopes. This provides information-rich datasets for comparative studies on cell wall changes and new insights to be gained [28]. To date, this method has successfully been applied to a number of grapevine studies, mainly analyzing grape berries [29-32] and one on the study of leaves (cultivar "Shiraz") [33]. These studies provide a valuable foundation, which can now be extended to pathogen infection research.

In this study, we applied carbohydrate microarray technology combined with other analytical cell wall methods to profile grapevine leaves for possible associations between cell wall polymer composition and grapevine downy mildew resistance. The Chinese native species (V. amurensis cv. "Shuanghong") with higher downy mildew resistance and European species (V. vinifera cv. "Cabernet Sauvignon") with lower resistance were chosen for leaf sampling. Furthermore, one hybrid (crossed from these two species) was also profiled for comparison as it showed partial resistance.

\section{Material and Methods}

\subsection{Plant Materials and Disease Resistance Assessment}

Vitis vinifera cv. "Cabernet Sauvignon" (susceptible, hereafter shortened as "Cab"), Vitis amurensis cv. Shuanghong (resistant, hereafter shortened as "SH") and their hybrid (partially resistant, hereafter shortened as "Cross") were maintained in the germplasm vineyard in the Center for Viticulture and Enology, Shanghai Jiao Tong University, Minhang District, Shanghai, China. To verify the resistance of selected cultivars, the fully expanded leaves (4th leaf from tip) were picked, and the leaf disks (9 discs each, approx. $11 \mathrm{~mm}$ in diameter) were generated using a cork borer. The leaf discs were then incubated in a Petri dish with moist filter paper underneath. The downy mildew broth $(35-\mu \mathrm{L}$, $10^{5}$ sporangia $/ \mathrm{mL}$ ) was inoculated into the center of the leaf discs, and the Petri dishes were incubated in a culture chamber at $22{ }^{\circ} \mathrm{C}$ with a photoperiod of $16 / 8 \mathrm{~h}$ (light/dark, respectively) for 7 days. The infection was investigated using microscopy, and the severity index was calculated according to Yu et al. [15].

\subsection{Cell Wall Preparation}

The grapevine leaves ( 3 biological replicates) were processed to alcohol insoluble residue (AIR) [31] for later cell wall analysis. Briefly, after storage at $-80{ }^{\circ} \mathrm{C}$ overnight, leaf samples were ground with liquid nitrogen using a high-throughput Tissue-Lyser (JXFSTRP series, Shanghai Jingxin Industrial Development Co. Ltd., Shanghai, China) for $30 \mathrm{~s}$ at $50 \mathrm{~Hz}$. In order to deactivate any endogenous enzymes, four volumes of $70 \%$ ethanol were added to the homogenized samples and then incubated at $95^{\circ} \mathrm{C}$ for $15 \mathrm{~min}$ using a water bath. The insoluble residue was recovered by centrifugation and then sequentially washed with Methanol, Chloroform, Acetone ( $2 \mathrm{~h}$ each and the pelleted residue retained after centrifugation). Finally, the washed residue was dried under a fume-hood and then re-suspended with the same volume of $\mathrm{dH}_{2} \mathrm{O}$, stored at $-80{ }^{\circ} \mathrm{C}$, before being freeze-dried to form AIR powder.

\subsection{Comprehensive Microarray Polymer Profiling (CoMPP)}

CoMPP was performed on the AIR sourced from the grapevine leaves [28]. Briefly, $10 \mathrm{mg}$ of AIR was firstly extracted with CDTA (diamino-cyclohexane-tetraacetic acid, $50 \mathrm{mM}, \mathrm{pH} 7.5)$, and later, an alkali extraction using $\mathrm{NaOH}\left(4 \mathrm{M}+0.1 \% \mathrm{NaBH}_{4}\right)$ was performed. These two solvents were routinely used for obtaining the pectin-rich fraction (CDTA) and the hemicellulose fraction $(\mathrm{NaOH})$ [28-31]. Each extraction was carried out in a $300 \mu \mathrm{L}$ solution, and the tubes (each containing a glass bead) were agitated at a frequency of $30 \mathrm{~Hz}$ for $2 \mathrm{~min}$ followed by $6 \mathrm{~Hz}$ for $2 \mathrm{~h}$. This was performed sequentially for each extract, so a total of $300 \mu \mathrm{L}$ CDTA extract and $300 \mu \mathrm{L} \mathrm{NaOH}$ extract was obtained from $10 \mathrm{mg}$ AIR. Each sample was prepared as 4 dilutions (first: 1:1, followed by serial five-fold 
dilutions of the preceding sample) before they were pipetted into 384-microwell plates. All of the samples (including dilutions) were then printed onto nitrocellulose membranes (pore size $0.45 \mathrm{~mm}$, Whatman) using a microarray instrument (Marathon, Arrayjet, Roslin, UK). The printed arrays were firstly blocked with phosphate buffered saline (140 mM $\left.\mathrm{NaCl}, 10 \mathrm{mM} \mathrm{Na}_{2} \mathrm{HPO}_{4}, 2,7 \mathrm{mM} \mathrm{KCl}, 1.7 \mathrm{mM} \mathrm{KH}_{2} \mathrm{PO}_{4}, \mathrm{PH} 7.5\right)$ with $5 \%(w / v)$ low-fat milk powder for $1 \mathrm{~h}$ followed by an overnight incubation at $5{ }^{\circ} \mathrm{C}$ with selected polysaccharide monoclonal antibodies (mAbs) or carbohydrate binding modules (CBMs) (see Table 1). The secondary binding was later performed in PBS $+5 \%$ Milk powder for $2 \mathrm{~h}$ with anti-rat, antimouse, or anti-His tag antibodies conjugated with alkaline phosphatase (Sigma) diluted 1:5000 (anti-mouse and anti-rat) or 1:1500 (anti-His tag). Arrays were washed in PBS and then developed in a chromogenic solution (5-bromo-4-chloro-3-indolylphaphate and nitro blue tetrazolium in alkaline phosphatase buffer $(100 \mathrm{mM} \mathrm{NaCl}, 100 \mathrm{mM}$ diethanolamine, $5 \mathrm{mM} \mathrm{MgCl}_{2}, \mathrm{pH}$ 9.5). The arrays were dried and scanned by a Cano Scan $8800 \mathrm{~F}$ scanner (SØborg, Denmark) with a signal intensity at 2400 dots per inch (dpi) and saved as a TIFF image. The probed arrays were quantified by using Array-ProAnalyzer 6.3 (Media Cybernetics, Rockville, MD, USA) software. The data were presented in a heatmap format, as the relative percentage distribution between the samples and antibodies, where the maximal mean spt signal intensity was set to $100 \%$, and the rest of values were normalized accordingly. A cut-off of $5 \%$ was applied to limit the signal noise.

\subsection{Gas Chromatography-Mass Spectrometry (GC-MS) for Monosaccharides}

The monosaccharide composition of grapevine leaf AIR was determined by using GCMS [31]. Briefly, $5 \mathrm{mg}$ of AIR was hydrolyzed with $2 \mathrm{M}$ Trifluoroacetic acid (TFA) at $110{ }^{\circ} \mathrm{C}$ for $2 \mathrm{~h}$ in the screwed tubes. The tubes were then cooled and centrifuged to collect the supernatant. The soluble monosaccharides in the supernatant were converted to methoxy sugars using $1 \mathrm{M}$ methanolic $\mathrm{HCl}$ at $80^{\circ} \mathrm{C}$ for $16 \mathrm{~h}$. The methoxy sugars were then used to perform the silylation by adding a pre-mixed solution (HMDS + TMCS + Pyridine, 3:1:9, Sylon HTP kit; Sigma-Aldrich, MO, USA) and then incubated at $80^{\circ} \mathrm{C}$ for $20 \mathrm{~min}$. The TMS glycosides were dissolved in cyclohexane and injected onto a $7890 \mathrm{~B}$ (Agilent, Palo Alto, CA, USA) gas chromatograph coupled to an Agilent 5877 MS Mass spectrometer. The GC/MS was performed at the Instrumental Analysis Center, Shanghai Jiao Tong University. A sugar mixture that contained 7 main monosaccharides (arabinose, rhamnose, xylose, galactose, galacturonic acid, mannose, glucose) was diluted to five concentrations, and underwent the same process (silylation and GC-MS) for creating the standard curves. The main monosaccharides from leaf AIR were quantified using established standard curves and myo-inositol as the internal standard.

\subsection{Fourier Transform Infrared (FTIR) Spectroscopy}

AIR sourced from grapevine leaves was scanned using Nicolet 6700 Fourier Transform Infrared Spectroscopy (Thermo Scientific, MA, USA) containing a Golden Gate Diamond Attenuated Total Reflectance (ATR) accessory with a type II diamond crystal; the spectra between 4000 and $650 \mathrm{~cm}^{-1}$ were recorded with a Geon-KBr beam splitter and DTGS/Csl detector. Each measurement consisted of 128 co-added scans, and the spectral data were processed using OMNIC software.

\subsection{Univariate Statistical and Multivariate Data Analysis}

All samples were analyzed for statistical significance by using Microsoft Excel 2020, and Univariate statistical analyses were performed (ANOVA, with $p=0.05$ ). Multivariate analysis for CoMPP raw data was performed with the SIMCA 14 software package (Sartorium Stedim Biotech-Umetrics AB, Umea, Sweden). 
Table 1. mAbs and CBMs used in the CoMPP analysis. HG: homogalacturonan; RG I: Rhamnogalacturonan I.

\begin{tabular}{|c|c|c|}
\hline Code & Specificity & Group \\
\hline JIM5 & Binds to partially methyl esterified HG & \multirow{6}{*}{ HG } \\
\hline JIM7 & Binds to heavily methyl esterified HG & \\
\hline LM18 & $\begin{array}{l}\text { Binds to de-esterified } \mathrm{HG} \text {, higher affinity to shorter } \\
\text { chain (DP }<4)\end{array}$ & \\
\hline LM19 & $\begin{array}{l}\text { Binds to de-esterified HG, higher affinity to longer } \\
\text { chain }(\mathrm{DP}>4)\end{array}$ & \\
\hline LM20 & Binds to methyl-esterified HG & \\
\hline LM8 & Binds to xylogalacturonan & \\
\hline INRA-RU1 & $\begin{array}{l}\text { Binds to unbranched region of RGI, need }>6 \\
\text { disaccharide backbone repeats, maximum binding to } \\
\text { DP }=14\end{array}$ & \multirow{6}{*}{ RGI and side chains } \\
\hline INRA-RU2 & $\begin{array}{c}\text { Binds to unbranched region of RGI, significant } \\
\text { binding to } 2 \text { disaccharide backbone repeats, need at } \\
\text { least DP }=4\end{array}$ & \\
\hline LM5 & Binds to (1-4)- $\beta$-D-galactan & \\
\hline LM6 & Binds to $(1,5)-\alpha$-L-arabinan, may bind to AGP & \\
\hline LM13 & $\begin{array}{l}\text { Binds to linear arabinan, highly sensitive } \\
\text { to arabinanase }\end{array}$ & \\
\hline LM16 & Binds to galactan stub & \\
\hline LM21 & $\begin{array}{l}\text { binds to mannans, glucomannans, and } \\
\text { galactomannans. Binds most strongly to } \\
\text { mannotetraose and mannopentaose. }\end{array}$ & \multirow{7}{*}{ Hemicellulose } \\
\hline BS-400-2 & Binds to (1-3)-B-D-glucan & \\
\hline LM15 & Binds to xyloglucan, $\mathrm{XXXG}$ motif & \\
\hline LM24 & Binds to XLLG or XXLG & \\
\hline LM25 & Binds to xyloglucan/unsubstituted glucan, & \\
\hline LM10 & (1-4)-ß-D-xylan & \\
\hline LM11 & $\begin{array}{l}\text { bind to unsubstituted xylans and arabinoxylans } \\
\text { carrying a low degree of arabinose substitution }\end{array}$ & \\
\hline СВМЗа & $\begin{array}{l}\text { Binds to crystalline cellulose and can detect cellulose } \\
\text { in both in vitro assays and directly in plant materials }\end{array}$ & Cellulose \\
\hline JIM8 & Arabinogalactan protein & \multirow{7}{*}{ Glycoprotein } \\
\hline JIM13 & Arabinogalactan protein & \\
\hline JIM15 & Arabinogalactan protein & \\
\hline JIM16 & Arabinogalactan protein & \\
\hline JIM17 & Arabinogalactan protein & \\
\hline LM2 & Arabinogalactan protein & \\
\hline MAC207 & Arabinogalactan protein & \\
\hline
\end{tabular}

\section{Results and Discussion}

3.1. Downy Mildew Resistance Measurement of Leaf Disks Sourced from the Two Grapevine Cultivars and the Hybrid Cross

Leaves from cultivar "SH", "Cab" and "Cross" were subjected to downy mildew resistance measurement before implementing cell wall analysis. The inoculation of Plasmopara viticola onto the three cultivars is shown in Figure 1 . The visual observation clearly 
indicated that cultivar " $\mathrm{SH}$ ' showed high resistance to mildew and cultivar "Cab" showed the most susceptibility, whereas the cultivar "Cross" (bred from "SH" and "Cab") showed partial resistance. The disease severity index was calculated according to Yu et al. [15] and showed similar trends by visual observation (data not shown); these results generally confirmed the previous finding [15] and provide validation of the chosen samples for later cell wall analysis.

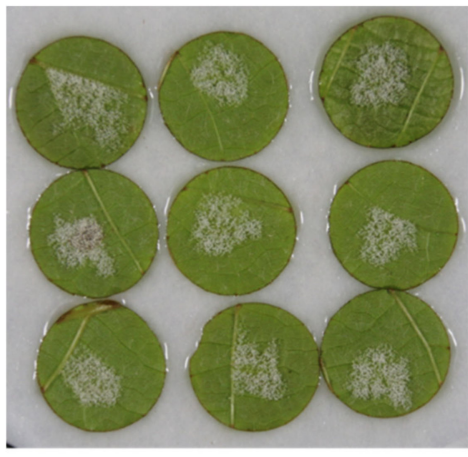

'Cab'

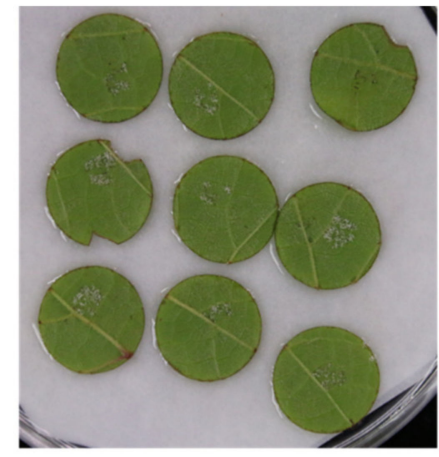

'Cross'

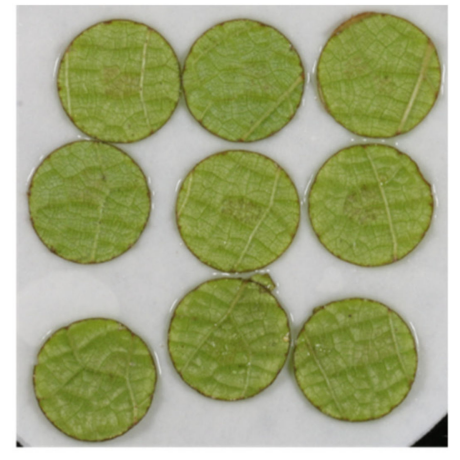

'SH'

Figure 1. Grapevine downy mildew symptoms on leaf disks with different sporulation density observed at 7 days postinoculation. "Cab": Vitis vinifera cv. "Cabernet sauvignon"; "SH": Vitis amurensis cv. "Shuanghong"; "Cross": the hybrid from "Cab" and "SH".

\subsection{Comprehensive Microarray Polymer Profiling (CoMPP)}

Comprehensive Microarray Polymer Profiling uses a set of mAbs and CBMs [28] to recognize the structural motifs of polysaccharides and glycoproteins present in extracted fractions from cell wall AIR samples. CoMPP generates datasets on the polysaccharide epitope occurrences rather than their monosaccharide composition, and, therefore, provides in-depth information on the cell wall epitope structure based on antibody characterisation. In this study, two sequentially extracted fractions (CDTA and $\mathrm{NaOH}$ ) from the grapevine leaf cell wall AIR were used for analysis, and the datasets obtained were used for constructing the heatmaps and multivariate data analysis. The heatmap generated from the CDTA fraction of cultivar "Cab" was found to be rich in pectin, specifically in homogalacturonans (HGs) and rhamnogalacturonan I-associated polymers (Figure 2). The HGs were recognized by mAbs JIM5, JIM7, LM18, LM19 and LM20. The selection of various mAbs for HGs depends on their affinities to the pectin and the corresponding specific structures and conformations (Table 1). Another two mAbs (LM7 for partially methyl-esterified epitope of HG that results from non-blockwise de-esterification processes, and LM8 for xylogalacturonan) were also used in the analysis; however, a very weak signal was detected, and their relative abundance were recorded as zero in the heatmap due to the cut-off $(<5)$ imposed. The mAbs INRA-RU1 and RU2 were used for probing the grapevine leaf cell wall for the first time in this study, as the first CoMPP analysis on grapevine leaf was performed on the cultivar "Shiraz" without using any INRA RG I backbone mAbs [33]. The leaf cell wall profile shows relatively lower epitope abundance on RG I than HG compared to grape berry cell walls $[31,32,34]$; this indicates the tissue-specific feature of plant cell wall variation. Interestingly, INRA-RU2 shows much lower abundance than INRA-RU1. A previous specificity study showed that INRA-RU1 recognizes RG I with more than six disaccharide backbone repeats, but the affinity decreases steeply as the number of disaccharides increases beyond seven, whereas INRA-RU2 requires at least two disaccharides with the highest affinity to seven disaccharides [35]. The differences between the above two mAbs may be due to the higher avidity of INRA-RU1 to RGI, especially the acetylesterified RGI decorated with short galactan side chains [35]. In addition to the RG I main chain, the structural motif abundance of mAbs LM5 and LM6 also revealed the presence of galactan 
and arabinan structural motifs, consistent with branched pectin RG I domains. Apart from the pectin components, xyloglucan (recognized by mAbs LM15 and LM25) was also found in the CDTA fraction with a relatively low signal. This phenomenon was also found in a number of previous studies, which suggested the association between pectin and xyloglucan $[4,28,36,37]$. Furthermore, the structural motifs of glycoproteins have also been detected by mAbs JIM8 and JIM13; other mAbs for AGP showed relatively lower signals and then were cut off from heatmap (Figure 2). The CoMPP CDTA heatmap of "Cab" shows generally similar profiles to "Shiraz" [33] with the presence of some differences. In Shiraz leaf cell walls, relatively higher epitope abundance was detected on mAbs JIM7 and LM20, which recognize highly esterified HG; this may indicate that the esterification level is higher in Shiraz leaf pectin than that in Cabernet Sauvignon.

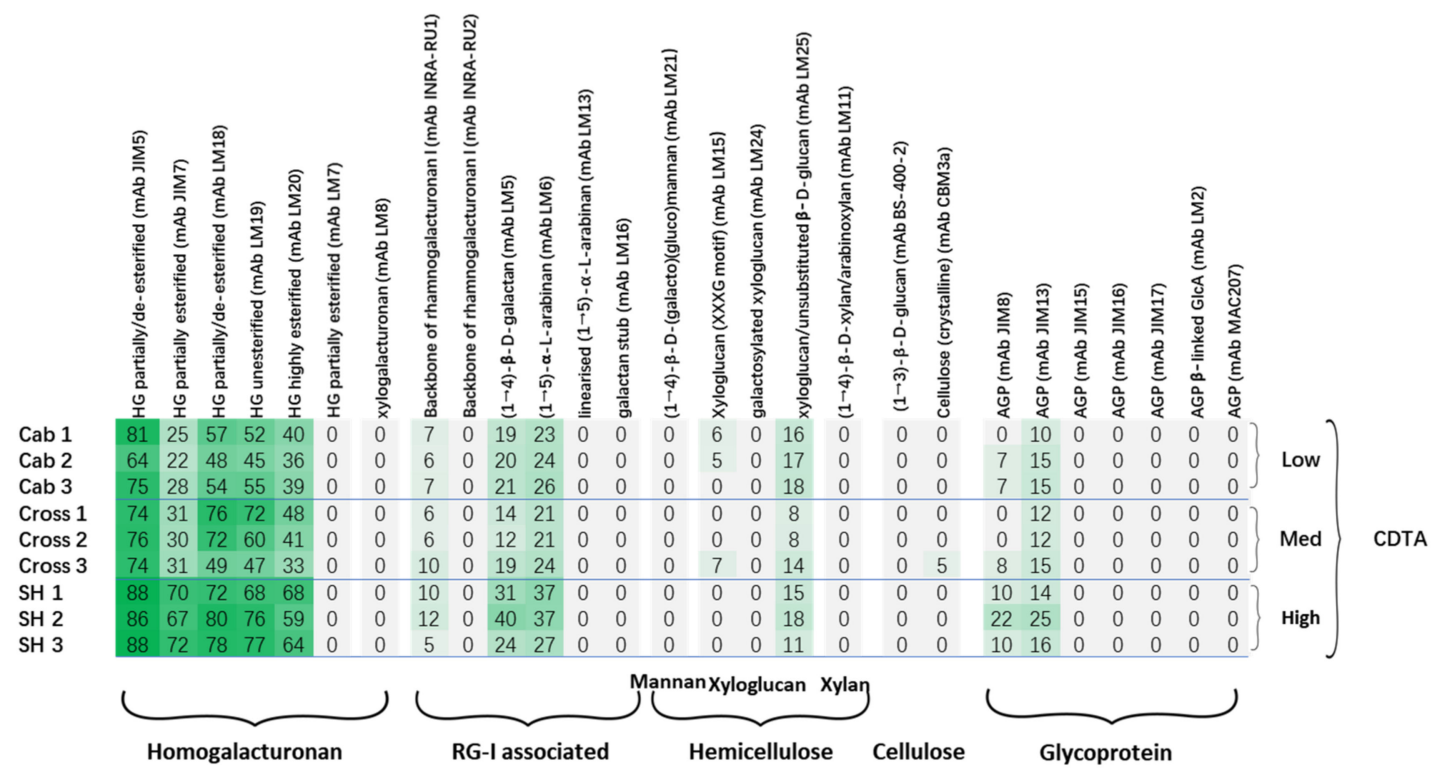

Figure 2. Comprehensive Microarray Polymer Profiling (CoMPP) analysis of CDTA extract of grapevine leaf cell wall AIR samples. The heatmap shows the relative abundance of plant cell wall glycan-associated structural motifs. The highest signal was set as 100, and others were adjusted accordingly; the color intensity is correlated to the mean spot signal. A cut-off $(<5)$ was applied.

In order to investigate the possible associations between cell wall polymers and grapevine downy mildew resistance, the cultivars with high resistance ("SH": Vitis amurensis cv. Shuanghong) and mid-resistance ("Cross": hybrid from Shuanghong and Cabernet Sauvignon) were also used for CoMPP analysis. In general, the heatmap (Figure 2) also shows the presence of HG, RG I, galactan, arabinan, xyloglucan and AGP epitopes in the CDTA fraction; however, a number of differences are noted compared to cultivar "Cab". Firstly, cultivar "SH" showed a generally higher epitope abundance on all the mAbs which recognize HG, especially those two mAbs (JIM7 and LM20) with higher affinity to methylesterifed HG. Interestingly, cultivar "Cross" showed a markedly higher abundance of mAbs JIM7 and LM20 than samples "Cab" but lower than samples "SH". In the plant cell, pectin is primarily synthesized in highly methyl-esterified form from the Golgi apparatus and then de-esterified with the action of endogenous pectin methyl esterases (PMEs); on the other hand, the plant could also secrete inhibitory proteins (PMEi) which block the activity of PME to precisely regulate the esterification level of the pectin during development. The status of pectin could also influence the porosity and integrity of the cell wall $[38,39]$. The pectin main chain with can be highly methylated will need the additional enzymes for thorough breakdown, and, therefore, decrease the availability of substrates targeted by other pathogenic cell wall-degrading enzymes (CWDEs), such as hemicellulases and cellulases [40]. Previous studies on some crops (tomato, cotton and wheat) have suggested that a high degree of esterification (DE) level of pectin is positively 
correlated with plant defense. [4,41,42]. In addition to differences in HG, cultivar "SH" showed the highest abundance for RG I and its associated side chains (arabinan and galac$\tan$ ) than the other two cultivars. RG I with side chains is usually called the hairy region of pectin; its complete deconstruction requires a set of lytic enzymes, such as RG lyases, arabinanases and galactanases. Previous studies have suggested the roles of arabinan and galactan side chains as cross-linked bridges between pectin and xyloglucan [23,43-45]. In addition to structural support, these side chains have been suggested to be involved in other biological activities, e.g., galactans could be used as structural markers, as their decreasing signal is found during fruit ripening [30]. Arabinan has been focused on for its potential roles in the stress tolerance of plants, such as in regard to drought [46] and salt stress [47]. However, currently no direct connection between arabinans and pathogen resistance has been confirmed. Apart from the pectin changes, the heatmap does not show notable differences in the epitope abundances of mAbs recognizing hemicelluloses (e.g., LM15 and LM25), even though some minor variations are present between the replicates of each of the cultivars. The comparison of glycoprotein profiles revealed the marked differences between three cultivars, and "SH" showed the highest abundance on the mAb JIM8 (which recognizes an AGP epitope). Recent reviews have suggested additional roles for AGPs in plant stress tolerance compared with more well-established roles in plant growth and development; AGP accumulation has been observed during a range of biotic and abiotic stresses [47-49].

The CoMPP heatmap gives a general overview of the polysaccharide profile for initial interpretation; however, it compresses the data for obtaining the relative values, and numerous variables (mAb abundance) can lead to a greater difficulty in visually inspecting datasets for differences. Thus, multivariate data analysis was routinely applied to the raw data to provide additional information (Figure 3). SIMCA software was used in this study to implement an unsupervised method (principal component analysis, PCA), in order to obtain an unbiased overview of the data structure. The raw CoMPP dataset was pre-processed in Microsoft Excel, and the mAbs were set as variables. The pre-processed dataset was then transferred to SIMCA to construct the PCA plot. The algorithms, if PCA found the maximum variance in the data assigning it to principal component 1 (PC1), then proceeded to PC2, PC3, etc. In this study, the PCA score plot, which contained two components (PC1 and PC2) with high quality (Figure 3A), was constructed; the score plot shows that three cultivars were clustered into three groups, and cultivar "SH" was separated from others $(\mathrm{PC} 1=41.6 \%$ ). The loading plot (Figure $3 \mathrm{~B}$ ) shows that the variables (mAbs) that drive this separation mainly include HG, RG I with associated side chains and AGPs. Interestingly, two replicates of cultivar "Cross" sit at the same side as cultivar "SH 1" and "SH 2" and the major variables driving this separation in the vertical dimension $(\mathrm{PC} 2=26.3 \%)$ are mAbs LM18 and LM19, which recognize the partially esterified HG. Further group-to-group (SH to Cross) comparisons suggest that corresponding variables include JIM7 and LM 20, which recognize methylesterifed HG (data not shown); this again supports the heatmap datasets. In addition to pectin, mAb BS-400-2 (recognizes callose), which did not show zero on heatmap, however, shows its association with other pectin recognizing $\mathrm{mAbs}$ in the PCA plot. Callose has been well documented in many studies for its roles in plant/microbial interactions; it has been found to be deposited around the infection sites to block the pathogens $[15,40]$.

The CoMPP datasets of the $\mathrm{NaOH}$ fraction of the three cultivars yielded a heatmap (Figure 4) rich in hemicellulosic polymers, including mannans (mAb LM21), xyloglucan (mAbs LM15, LM24 and LM25) and xylan (mAb LM11). Glucan, cellulose and AGP were also detected by mAbs (mAbs BS-400-2, CBM3a, JIM8, JIM13), as well as the signals of galactan (mAb LM5) and arabinan (mAbs LM6 and LM13); these may again support the hypothesis that these side chains act as the linkages between RG I and hemicellulosic polymers [45]. The comparison between cultivars revealed the increasing trend of xyloglucan (with XXXG motif, recognized by mAb LM15). Hemicellulose polymers have been suggested to play critical roles in the strengthening of the plant cell wall structure, therefore 
elevating the plant resistance to stress. For example, the marked increase in arabinoxyloglucan has been stated to positively correlated with the resistance of tobacco to Botrytis cinerea [50]; the silencing of xylanases activity increased the xylan content and silique dehiscence resistance [51]; and a generally enriched hemicellulose was found in resistant wheat cultivar compared to cultivar susceptible to Fusarium Head Blight [52]. In addition to mAbs LM15, another hemicellulosic polymer, (galacto)(gluco)mannan (mAb LM21), showed a similar increasing pattern. Interestingly, similar to the CDTA fraction (Figure 2), an increasing trend was also observed for AGP epitope abundance, recognized by both mAbs JIM8 and JIM13, which again suggested their possible roles in grapevine/downy mildew interactions. To obtain further information on possible associations between polymers, the PCA score plot (Figure 5A) and loading plot (Figure 5B) were constructed from the CoMPP raw datasets of the $\mathrm{NaOH}$ fraction. In Figure 5A, it is very clear that those samples were well clustered into three groups on the horizontal dimension; cultivar " $\mathrm{SH}^{\prime}$ has distinct distance from cultivar "Cab", whereas cultivar "Cross" sits between them (PC1 explained by $28.6 \%$ variance). In the loading plot (Figure 4 ), the main variables driving this separation include AGP, mannan, xyloglucan and cellulose, which again support the heatmap datasets (Figure 4).

PCA-X: COMPP pf CDTA fraction from grapevine leaf AIR

A

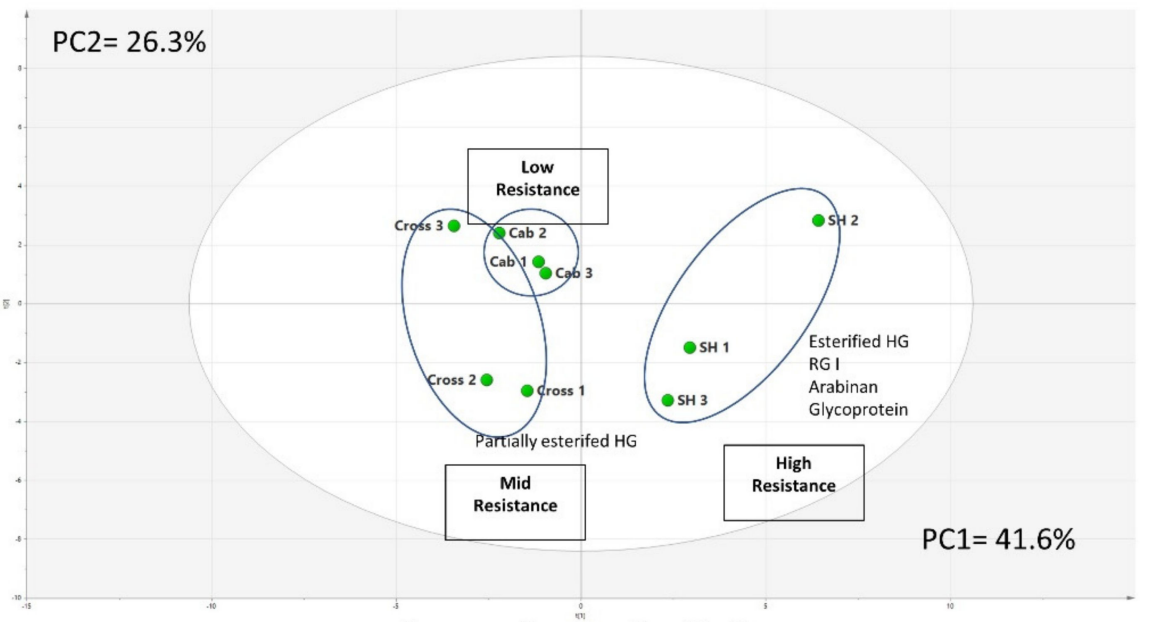

B

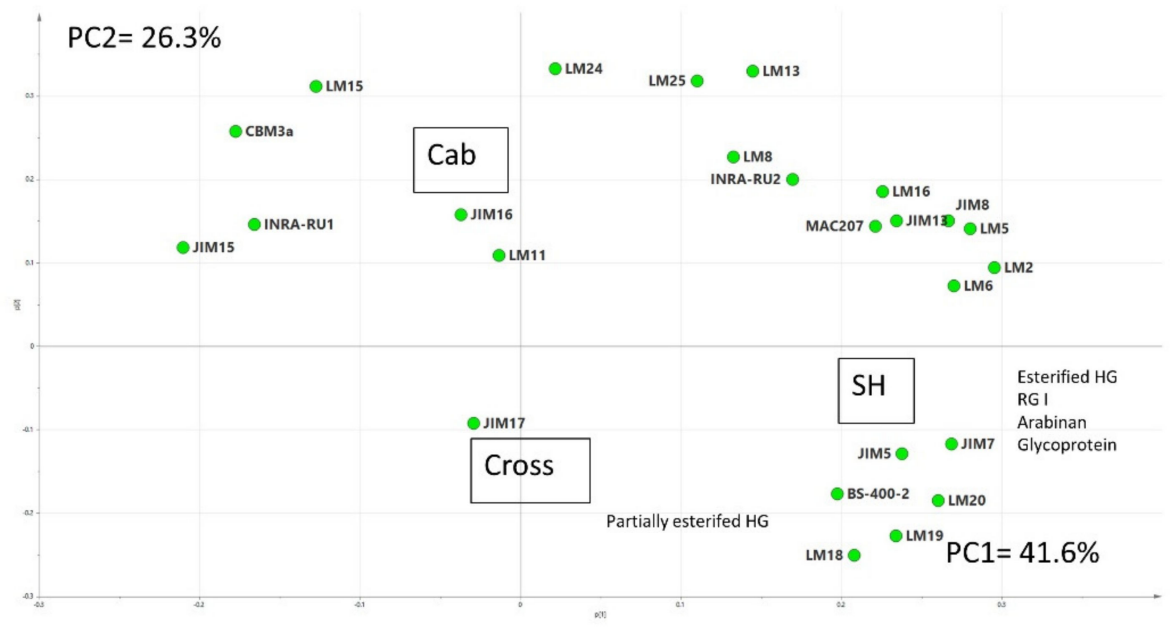

Figure 3. PCA score plot (A) and loading plot (B) of the CDTA (pectin-rich) extract from AIR sourced from grapevine leaves. 


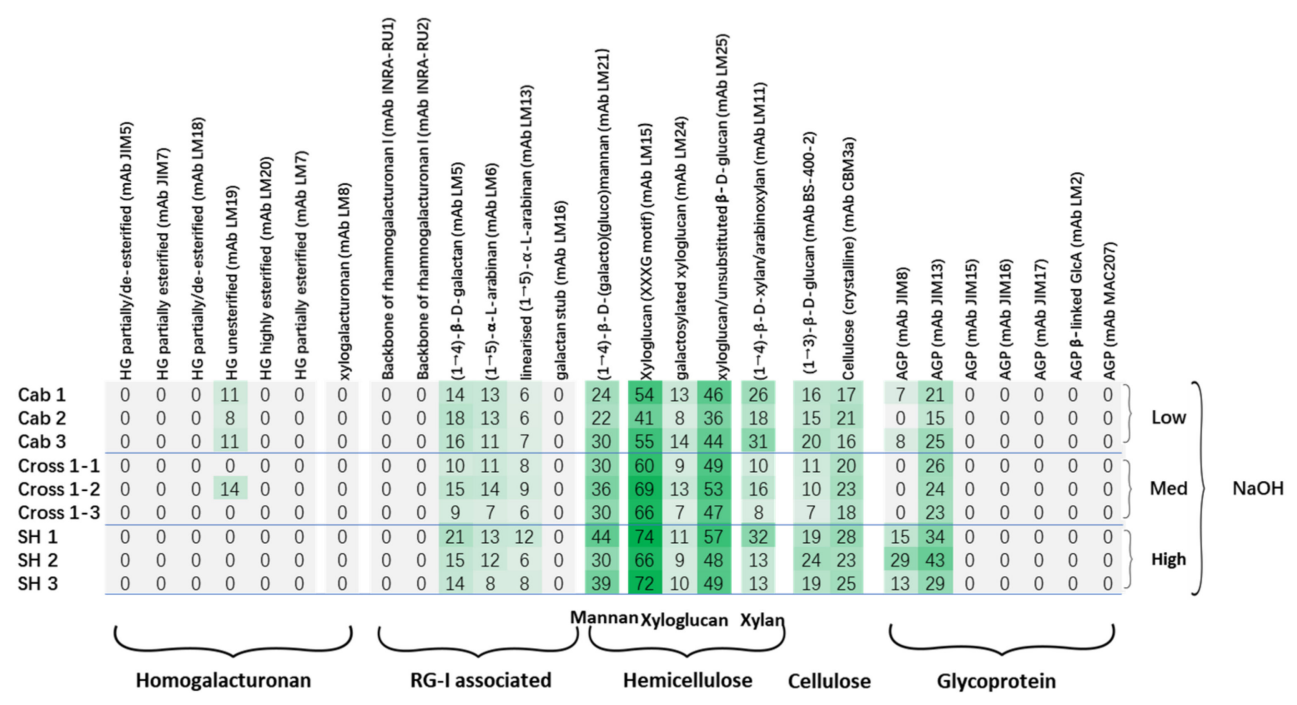

Figure 4. Comprehensive Microarray Polymer Profiling (CoMPP) analysis of $\mathrm{NaOH}$ extract of grapevine leaf cell wall AIR samples. The heatmap showed the relative abundance of plant cell wall glycan-associated structural motifs. The highest signal was set as 100, and others were adjusted accordingly; the color intensity is correlated to the mean spot signal. A cut-off $(<5)$ was applied.

\subsection{Monosaccharide Composition of Leaf Cell Wall Materials Using GC-MS}

Gas chromatography (GC) has been routinely applied in cell wall analysis; it gives additional monosaccharide composition data for the validation of CoMPP analysis $[32,33,37]$. In this study, GC was applied to the most distinct samples ("SH" and "Cab"), and seven monosaccharides were analyzed (Figure 6). In general, leaf AIR from two cultivars contains a substantial amount of GalA (ca. 35-40 mol.\%), with the presence of Ara (ca. 14-15\%), Rha (ca. 5-7\%) and Gal (ca. 13-14\%), which suggests that leaf cell walls contain homogalacturonan (HG), rhamnogalacturonan I (RG I) and possibly rhamnogalacturonan II (RG II). On the other hand, the presence of Xyl (ca. 11-12\%), Man (ca. 4-6\%) and Glc (ca. 12-14\%) suggests that xylan, xyloglucan and mannan are major components of the hemicellulosic fraction of grapevine leaf cell walls. These datasets show high similarity to the leaf sample of cultivar "Shiraz" [33], but different to the composition of tobacco leaves [36] and grape berry cell walls [37], this indicates the cell wall differences among the plant organs and tissues. Furthermore, the comparison between "Cab" and "SH" did not reveal significant differences among those monosaccharides; In addition to the markedly higher mol.\% of GalA in cultivar "SH", this may explain the generally higher abundance of mAbs that recognize HG (Figure 2). This result highlights the limitations of GC composition datasets, which tend not provide information on subtle structural differences, whereas CoMPP provides additional richer and complementary data on the polysaccharide structure by virtue of epitope abundance. In a previous study on grape berry cell wall deconstruction, the GC-MS did not show any significant changes between samples, whereas CoMPP was able to detect changes such as pectin de-esterification [37].

\subsection{IR Spectroscopy}

ATR-FT-MIR spectroscopy provides a fast and convenient method to detect the chemical functional groups present in cell wall samples [53]; it is usually applied in cell wall studies to provide a general overview of vibrational chemical bonds linked to polysaccharides and protein $[31,33]$. In this study, AIR samples sourced from cultivar "SH" and "Cab" were used for IR spectroscopy, generating wavescan spectral profiles (Figure 7) which can be used for comparisons. Two spectra were generated, both consisting of a number of maxima, including pectin $\mathrm{HG}$ at $1017 \mathrm{~cm}^{-1}$, xyloglucan at $1041 \mathrm{~cm}^{-1}$, amides at $1650 \mathrm{~cm}^{-1}$ and esterified pectin at $1740 \mathrm{~cm}^{-1}$ [53]. The comparison showed a similar spectral profile in general, which confirmed the finding from GC-MS and CoMPP, and reflects that bulk 
chemistry does not vary dramatically. However, few differences are worth noting: First, visual inspection indicated subtle difference in the shape of maxima at $1041 \mathrm{~cm}^{-1}$, which may suggest the structural differences in hemicellulosic polymers; this may be explained by the higher abundance of xyloglucan (with XXXG motif) found in Figure 4. The difference in maxima at $1017 \mathrm{~cm}^{-1}$ was also noted, which may indicate the higher pectin HG content in the "SH" AIR sample; however, the supporting data will be needed in future work as the GC-MS and CoMPP mainly focused on the non-cellulose fractions. Interestingly, the most significant difference between the two spectra is the maxima $\left(1740 \mathrm{~cm}^{-1}\right)$, which refer to esterified HG. This again supports the finding from Figures 2 and 3 that indicated the cultivar "SH" has a higher abundance of esterified HG.

PCA-X: CoMPP of $\mathrm{NaOH}$ fraction from grapevine leaf AIR

A

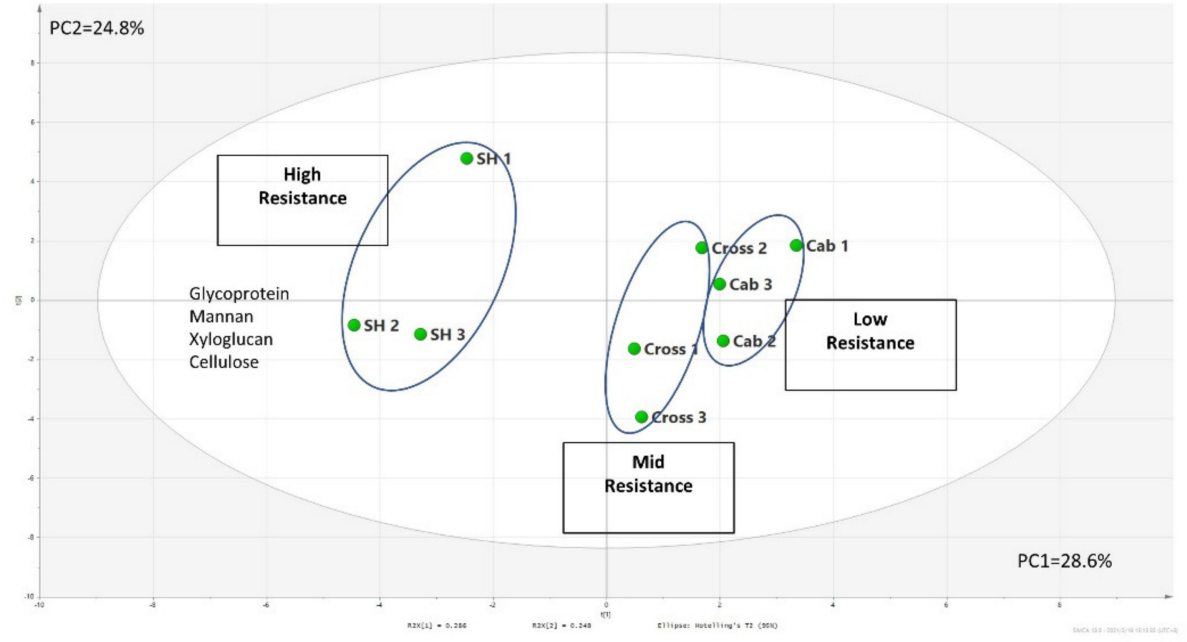

B

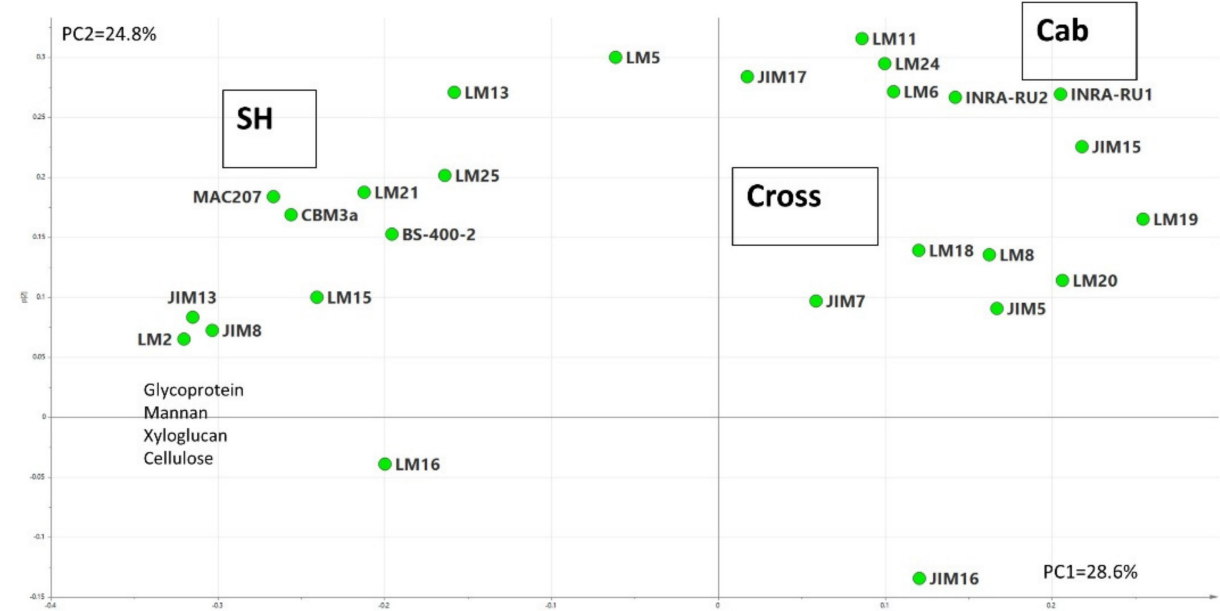

Figure 5. PCA score plot (A) and loading plot (B) of the $\mathrm{NaOH}$ (hemicellulose-rich) extract from AIR sourced from grapevine leaves. 


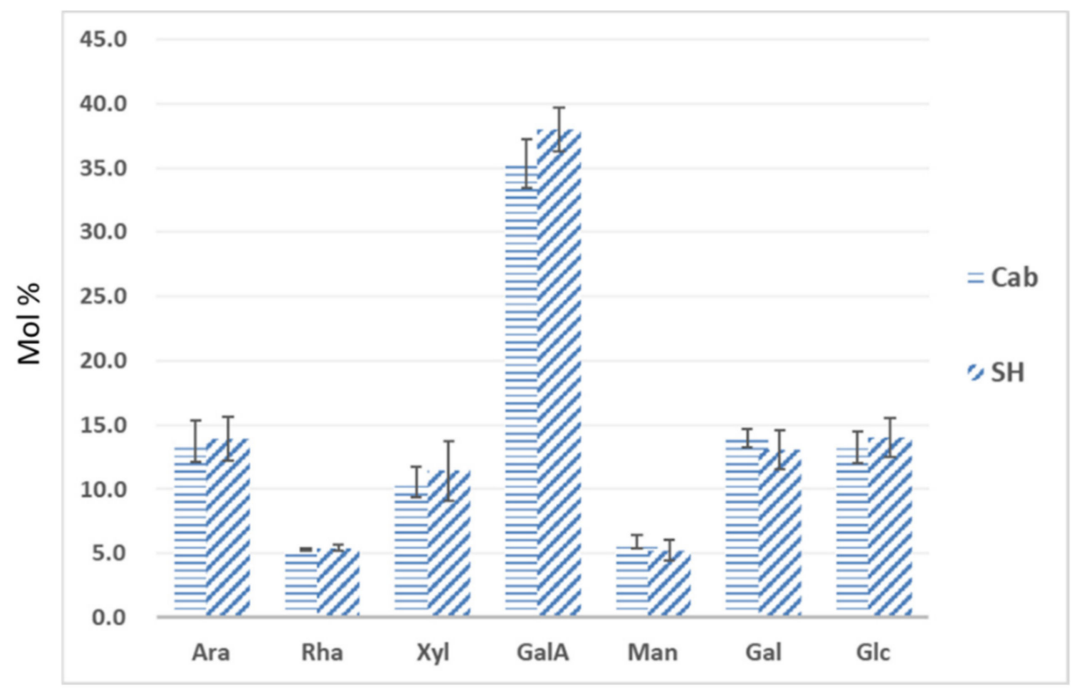

Figure 6. The monosaccharide composition of AIR sourced from grapevine leaves. The composition is expressed in relative $\mathrm{mol} \%$ of seven main monosaccharides present in grapevine leaf cell wall. Ara: arabinose; Rha: rhamnose; Xyl: xylose; GalA: galacturonic acid; Man: mannose; Gal: galactose; Glc: glucose. Error bars represent the standard derivation of the mean value of three biological repeat.

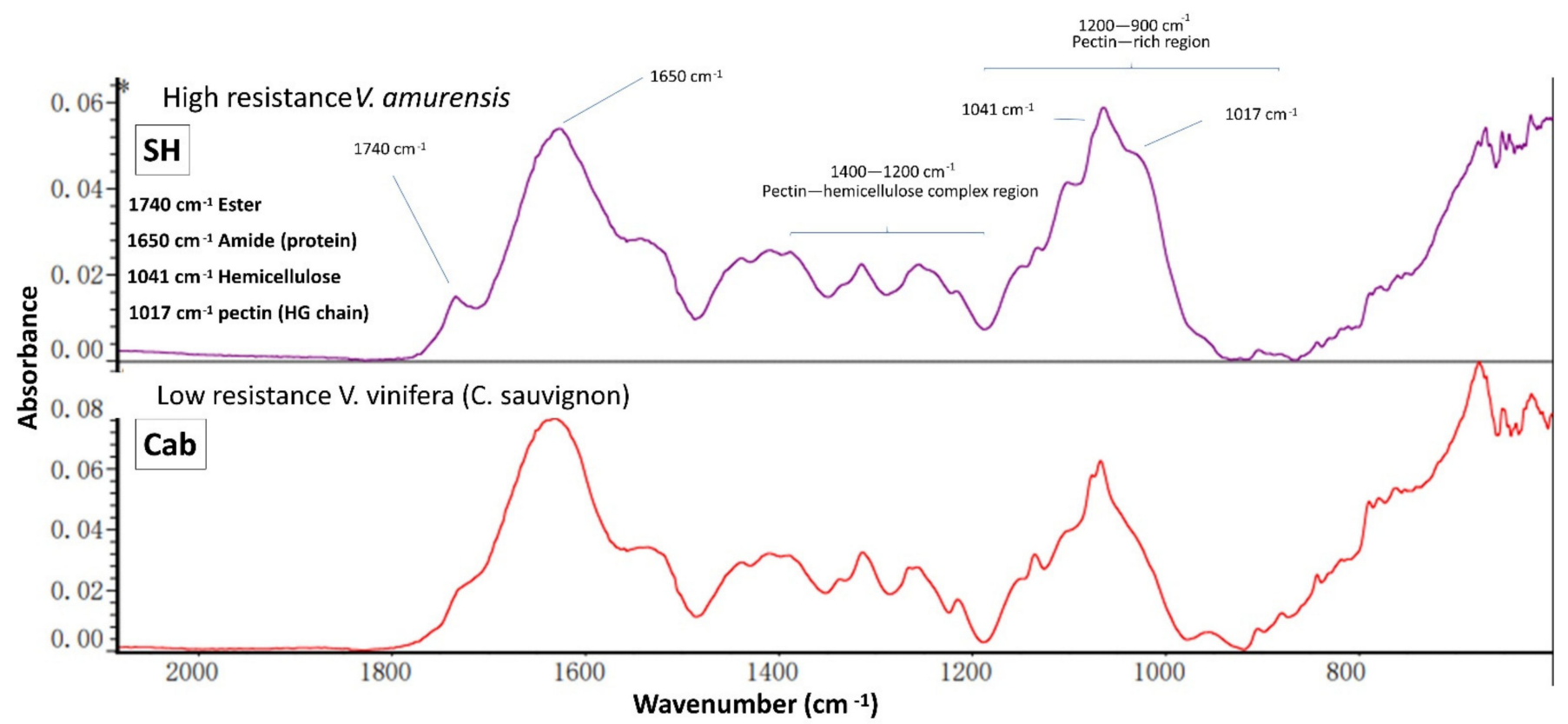

Figure 7. Fourier transform infrared (FT-IR) spectra generated from the AIR samples sourced from grapevine leaves.

\section{Conclusions}

In order to achieve the successful penetration of plant tissue, pathogenic microorganisms (e.g., fungi) are found to employ various methods in their arsenal. Among these, the secretion of cell wall-degrading enzymes (CWDEs) is recognized as an effective and precise way for unravelling and degrading one of the most complex structures in the nature. Compared to rot fungi in general, which secretes a wide range of CWDEs, as is the case for necrotrophs, for thorough degradation, the bioinformatic genome and transcriptome comparisons suggest that the relatively lower diversity of lytic enzymes is expressed in the oomycete family [54]. Thus, the interactions between plants and oomycetes in the cell wall battlefield may vary during fungal infection. However, there is very limited information on the host resistance from the viewpoint of the plant cell wall structure. Previous studies 
found that grape hybrids which were bred from native species may acquire parental resistance to differing degrees. In this study, cutting-edge cell wall profiling tools were applied to selected grapevine leaf samples to investigate the possible correlations between grape leaf cell wall polymers and downy mildew resistance.

The carbohydrate microarray provided much richer information than more classical methods (GC-MS and FTIR), and revealed a number of differences between the uninfected leaves of Vitis amurensis cv. "Shuanghong" (resistance) and Vitis vinifera cv. "Cabernet Sauvignon" (susceptible), with the aid of multivariate data analysis tools. Significantly higher amounts of methyl esterified HG were found in cultivar " $\mathrm{SH}^{\text {", }}$ and the increasing trend of this component from cultivar "Cab" and "Cross" (hybrid with moderate resistance) to "SH" may suggest its potential role as a structural biomarker in downy mildew resistance; this was also supported by FTIR spectral data of the functional chemical groups. Similar patterns were also noted for xyloglucan with the XXXG motif. Arabinogalactan proteins

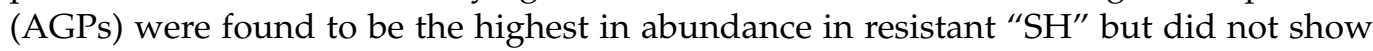
significant differences between "Cab" and "Cross".

In summary, the higher esterification level of HG, high content of mannan and xyloglucan (XXXG) could be the correlated with the native Chinese grapevine (Vitis amurensis $\mathrm{cv}$. "SH") natural resistance to downy mildew, and may be inherited from the native grapevine species through breeding. However, are these differences common to other wild grapevine species with similar resistances? How are these polymers regulated in wild grapevines during development? In order to answer these questions, the relevant genes behind these cell wall polymer changes will need to be focused on, e.g., the balance in expression of endogenous pectin methyl esterase (PME) and PME-inhibiting proteins (PMEI). Furthermore, in addition to the structural enhancement of the cell wall ahead of infection, we do not know how these wall polymers are altered by mildew infection/invasion. Future work will be needed to observe the induced changes of these cell wall components during mildew infection, as well as relevant factors (e.g., lytic enzymes), for obtaining an in-depth understanding of the complex network involved in cell wall regulation and molecular architecture. This is the first comprehensive comparison study of leaf cell wall polysaccharide polymer/protein variation from Vitis species and hybrids differing in their resistance to grapevine downy mildew. This provides important baseline reference datasets for future investigations on other biotic and abiotic stresses important in agricultural grape production.

Author Contributions: Y.G. and X.Y. designed and conducted the experiments, P.F., W.W. and B.Y. did the breeding work, germplasm maintenance and infection experiments. H.J. performed the GC-MS and IR analysis. J.H. and B.J. performed the CoMPP analysis. Y.G. analysed the data and drafted the manuscript. W.Y., S.S., J.P.M. and J.L. contributed to the improvement of the manuscript. All authors have read and agreed to the published version of the manuscript.

Funding: This work was supported by the Shanghai Agriculture Applied Technology Development Program, China (Grant No. 2018-02-08-00-08-F01552); National Natural Science Foundation of China (No. 31801830 and 31701775); the Shanghai Jiao Tong University New Scholar Start-Up Fund (AF1500068); Shanghai Municipal Commission for Science and Technology (18391900400); China Agriculture Research System (CARS-29-yc-2).

Institutional Review Board Statement: Not applicable.

Informed Consent Statement: Not applicable.

Data Availability Statement: Not applicable.

Conflicts of Interest: The authors declare no conflict of interests. 


\section{References}

1. Moore, J.P.; Divol, B. Tracking the careers of grape and wine polymers using biotechnology and systems biology. In Biotechnology in Functional Foods and Nutraceuticals; Bagchi, D., Lau, F.C., Ghosh, D.K., Eds.; CRC Press Inc.: Boca Raton, FL, USA, 2010; pp. 389-406.

2. Kubicek, C.P.; Starr, T.L.; Glass, N.L. Plant cell wall-degrading enzymes and their secretion in plant-pathogen fungi. Annu. Rev. Phytopathol. 2014, 52, 427-451. [CrossRef] [PubMed]

3. Boevink, P.C.; Mclellan, H.; Gilroy, E.M.; Naqvi, S.; He, Q.; Yang, L.; Wang, X.; Turnbull, D.; Armstrong, M.R.; Tian, Z.; et al. Oomycetes seek help from the plant: Phytophthora infestans effectors target host susceptibility factors. Mol. Plant 2016, 9, 636-638. [CrossRef] [PubMed]

4. Johnsen, H.R.; Striberny, B.; Olsen, S.; Vidal-Melgosa, S.; Fangel, J.U.; Willats, W.G.T.; Rose, J.K.C.; Krause, K. Cell wall composition profiling of parasitic giant dodder (Cuscuta reflexa) and its hosts: A priori differences and induced changes. New Phytol. 2015, 207, 805-816. [CrossRef]

5. Olsen, S.; Striberny, B.; Hollmann, J.; Schwacke, R.; Popper, Z.A.; Krause, K. Getting ready for host invasion elevated expression and action of xyloglucan endotransglucosylases/hydrolases in developing haustoria of the holoparasitic angiosperm Cuscuta. J. Exp. Bot. 2016, 67, 695-708. [CrossRef]

6. Bacete, L.; Melida, H.; Miedes, E.; Molina, A. Plant cell wall-mediated immunity: Cell wall changes trigger disease resistance responses. Plant J. 2018, 93, 614-636. [CrossRef]

7. Beck, M.; Zhou, J.; Faulkner, C.; Maclean, D.; Robatzek, S. Spatio-temporal cellular dynamics of the Arabidopsis flagellin receptor reveal activation status-dependent endosomal sorting. Plant Cell. 2012, 24, 4205. [CrossRef] [PubMed]

8. De Jonge, R.; van Esse, H.P.; Kombrink, A.; Shinya, T.; Desaki, Y.; Bours, R.; Van Der Krol, S.; Shibuya, N.; Joosten, M.H.A.J.; Thomma, B.P.H.J. Conserved fungal lysm effector ecp6 prevents chitin-triggered immunity in plants. Science 2010, $329,953$. [CrossRef]

9. Hernández Blanco, C.; Feng, D.X.; Hu, J.; Sánchez vallet, A.; Deslandes, L.; Llorente, F.; Berrocal-Lobo, M.; Keller, H.; Barlet, X.; Sánchez-Rodríguez, C.; et al. Impairment of cellulose synthases required for Arabidopsis secondary cell wall formation enhances disease resistance. Plant Cell. 2007, 19, 890-903. [CrossRef]

10. Sicilia, F.; Fernandez-Recio, J.; Caprari, C.; De Lorenzo, G.; Tsernoglou, D.; Cervone, F.; Federici, L. The Polygalacturonaseinhibiting protein pgip2 of Phaseolus vulgaris has evolved a mixed mode of inhibition of endopolygalacturonase pg1 of Botrytis cinerea 1. Plant Physiol. 2005, 139, 1380-1388. [CrossRef]

11. Joubert, D.A.; Kars, I.; Wagemakers, L.; Bergmann, C.; Kemp, G.; Vivier, M.A.; Van Kan, J.A.L. A polygalacturonase-inhibiting protein from grapevine reduces the symptoms of the endopolygalacturonase BcPG2 from Botrytis cinerea in Nicotiana benthamiana leaves without any evidence for in vitro interaction. Mol. Plant-Microbe Interact. 2007, 20, 392-402. [CrossRef]

12. Federici, L.; Caprari, C.; Mattei, B.; Savino, C.; Di Matteo, A.; De Lorenzo, G.; Cervone, F.; Tsernoglou, D.; Staskawicz, B.J. Structural requirements of endopolygalacturonase for the interaction with PGIP (polygalacturonase- inhibiting protein). Proc. Natl. Acad. Sci. USA 2001, 98, 13425-13430. [CrossRef]

13. Alexandersson, E.; Becker, J.V.W.; Jacobson, D.; Nguema-Ona, E.; Steyn, C.; Denby, K.J.; Vivier, M.A. Constitutive expression of a grapevine polygalacturonase-inhibiting protein affects gene expression and cell wall properties in uninfected tobacco. BMC Res. Notes. 2011, 4, 493. [CrossRef]

14. Liu, N.; Zhang, X.; Sun, Y.; Wang, P.; Li, X.; Pei, Y.; Li, F.; Hou, Y. Molecular evidence for the involvement of a polygalacturonaseinhibiting protein, GhPGIP1, in enhanced resistance to Verticillium and Fusarium wilts in cotton. Sci. Rep. 2017, 7, 39840. [CrossRef]

15. Yu, Y.; Zhang, Y.L.; Yin, L.; Lu, J. The mode of host resistance to Plasmopara viticola infection of grapevines. Phytopathol. 2012, 102, 1094-1101. [CrossRef]

16. Burruano, S. The life-cycle of Plasmopara viticola, cause of downy mildew of vine. Mycologist 2000, 14, 179-182. [CrossRef]

17. Boso, S.; Santiago, J.L.; Martinez, M.C. Resistance of eight different clones of the grape cultivar Albariño to Plasmopara viticola. Plant Dis. 2004, 88, 741-744. [CrossRef] [PubMed]

18. Davidson, L.C. Variation within and between Vitis spp. for foliar resistance to the downy mildew pathogen Plasmopara viticola. Plant Dis. 2008, 92, 1577-1584. [CrossRef]

19. Unger, S.; Büche, C.; Boso, S.; Kassemeyer, H.H. The course of colonization of two different Vitis genotypes by Plasmopara viticola indicates compatible and incompatible host-pathogen interactions. Phytopathology 2007, 97, 780-786. [CrossRef]

20. Trouvelot, S.; Varnier, A.L.; Allègre, M.; Mercier, L.; Baillieul, F.; Arnould, C.; Gianinazzi-Pearson, V.; Klarzynski, O.; Joubert, J.M.; Pugin, A. A $\beta-1,3$ glucan sulfate induces resistance in grapevine against Plasmopara viticola through priming of defense responses, including HR-like cell death. Mol. Plant-Microbe Interact. 2008, 21, 232-243. [CrossRef] [PubMed]

21. Wu, J.; Zhang, Y.L.; Zhang, H.Q.; Huang, H.; Folta, K.M.; Lu, J. Whole genome wide expression profiles of Vitis amurensis grape responding to downy mildew by using Solexa sequencing technology. BMC Plant Biol. 2010, 10, 234-249. [CrossRef] [PubMed]

22. Vorwerk, S.; Somerville, S.; Somerville, C. The role of plant cell wall polysaccharide composition in disease resistance. Trends Plant Sci. 2004, 9, 203-209. [CrossRef]

23. Somerville, C.; Bauer, S.; Brininstool, G.; Facette, M.; Hamann, T.; Milne, J.; Osborne, E.; Paredez, A.; Persson, S.; Raab, T.; et al. Toward a systems approach to understanding plant cell walls. Science 2004, 306, 2206-2211. [CrossRef] [PubMed] 
24. Albersheim, P.; Darvill, A.; Roberts, K.; Sederoff, R.; Staehelin, A. Plant Cell Walls: From Chemistry to Biology; Garland Science: New York, NY, USA, 2011; pp. 365-407.

25. Marcus, S.E.; Blake, A.W.; Benians, T.A.S.; Lee, K.J.D.; Poyser, C.; Donaldson, L.; Leroux, O.; Rogowski, A.; Petersen, H.L.; Boraston, A.; et al. Restricted access of proteins to mannan polysaccharides in intact plant cell walls. Plant J. 2010, 64, 191-203. [CrossRef]

26. Ma, Q.-H.; Zhu, H.-H.; Qiao, M.-Y. Contribution of both lignin content and sinapyl monomer to disease resistance in tobacco. Plant Pathol. 2018, 67, 642-650. [CrossRef]

27. Yang, Y.; Yang, X.; Dong, Y.; Qiu, D. The Botrytis cinerea Xylanase BcXyl1 Modulates Plant Immunity. Front. Microbiol. 2018, 9 , 2535. [CrossRef] [PubMed]

28. Moller, I.; Sørensen, I.; Bernal, A.; Blaukopf, C.; Lee, K.; Øbro, J.; Pettolino, F.; Roberts, A.; Mikkelsen, J.D.; Knox, J.P.; et al. Highthroughput mapping of cell-wall polymers within and between plants using novel microarrays. Plant J. 2007, 50, 1118-1128. [CrossRef]

29. Gao, Y.; Fangel, J.U.; Willats, W.G.T.; Vivier, M.A.; Moore, J.P. Effect of commercial enzymes on berry cell wall deconstruction in the context of intravineyard ripeness variation under winemaking conditions. J. Agric. Food Chem. 2016, 64, 3862-3872. [CrossRef]

30. Moore, J.P.; Fangel, J.U.; Willats, W.G.T.; Vivier, M.A. Pectic-(1,4)-galactan, extensin and arabinogalactan-protein epitopes differentiate ripening stages in wine and table grape cell walls. Ann. Bot. 2014, 114, 1279-1294. [CrossRef] [PubMed]

31. Gao, Y.; Fangel, J.U.; Willats, W.G.T.; Vivier, M.A.; Moore, J.P. Dissecting the polysaccharide-rich grape cell wall changes during winemaking using combined high-throughput and fractionation methods. Carbohydr. Polym. 2015, 133, 567-577. [CrossRef] [PubMed]

32. Zietsman, A.J.J.; Moore, J.P.; Fangel, J.U.; Willats, W.G.T.; Vivier, M.A. Profiling the hydrolysis of isolated grape berry skin cell walls by purified enzymes. J. Agric. Food Chem. 2015, 63, 8267-8274. [CrossRef] [PubMed]

33. Moore, J.P.; Nguema-Ona, E.; Fangel, J.U.; Willats, W.G.; Hugo, A.; Vivier, M.A. Profiling the main cell wall polysaccharides of grapevine leaves using high-throughput and fractionation techniques. Carbohydr. Polym. 2014, 99, 190-198. [CrossRef]

34. Garrido-Bañuelos, G.; Buica, A.; Schückel, J.; Zietsman, A.J.J.; Willats, W.G.T.; Moore, J.P.; Du Toit, W.J. Investigating the relationship between grape cell wall polysaccharide composition and the extractability of phenolic compounds into Shiraz wines. Part I: Vintage and ripeness effects. Food Chem. 2019, 278, 36-46. [CrossRef]

35. Ralet, M.C.; Tranquet, O.; Poulain, D.; Moise, A.; Guillon, F. Monoclonal antibodies to rhamnogalacturonan I backbone. Planta 2010, 231, 1373-1383. [CrossRef]

36. Nguema-Ona, E.; Moore, J.P.; Fagerstrom, A.; Fangel, J.U.; Willats, W.G.; Hugo, A.; Vivier, M.A. Profiling the main cell wall polysaccharides of tobacco leaves using high-throughput and fractionation techniques. Carbohydr. Polym. 2012, 88, 939-949. [CrossRef]

37. Gao, Y.; Fangel, J.U.; Willats, W.G.T.; Vivier, M.A.; Moore, J.P. Dissecting the polysaccharide-rich grape cell wall matrix using recombinant pectinases during winemaking. Carbohydr. Polym. 2016, 152, 510-519. [CrossRef]

38. Marcus, S.E.; Verhertbruggen, Y.; Herve, C.; Ordaz-Ortiz, J.J.; Farkas, V.; Pedersen, H.L.; Willats, W.G.T.; Knox, J.P. Pectic homogalacturonan masks abundant sets of xyloglucan epitopes in plant cell walls. BMC Plant Biol. 2008, 8, 60. [CrossRef] [PubMed]

39. Herve, C.; Rogowski, A.; Blake, A.W.; Marcus, S.E.; Gilbert, H.J.; Knox, J.P. Carbohydrate-binding modules promote the enzymatic deconstruction of intact plant cell walls by targeting and proximity effects. Proc. Natl. Acad. Sci. USA 2010, 107, 15293-15298. [CrossRef] [PubMed]

40. Tingley, J.P.; Low, K.E.; Xing, X.; Abbott, D.W. Combined whole cell wall analysis and streamlined in silico carbohydrate-active enzyme discovery to improve biocatalytic conversion of agricultural crop residues. Biotechnol. Biofuels 2021, 14, 16. [CrossRef]

41. Volpi, C.; Janni, M.; Lionetti, V.; Bellincampi, D.; Favaron, F.; D’Ovidio, R. The ectopic expression of a pectin methyl esterase inhibitor increases pectin methyl esterification and limits fungal diseases in wheat. Mol. Plant-Microbe Interact. 2011, 24, 1012-1019. [CrossRef]

42. Liu, N.; Sun, Y.; Pei, Y.; Zhang, X.; Wang, P.; Li, X.; Li, F.; Hou, Y. A pectin methylesterase inhibitor enhances resistance to verticillium wilt. Plant Physiol. 2018, 176, 2202-2220. [CrossRef] [PubMed]

43. Coenen, G.J.; Bakx, E.J.; Verhoef, R.P.; Schols, H.A.; Voragen, A.G.J. Identification of the connecting linkage between homo- or xylogalacturonan and rhamnogalacturonan type I. Carbohydr. Polym. 2007, 70, 224-235. [CrossRef]

44. Zykwinska, A.; Thibault, J.F.; Ralet, M.C. Organization of pectic arabinan and galactan side chains in association with cellulose microfibrils in primary cell walls and related models envisaged. J. Exp. Bot. 2007, 58, 1795-1802. [CrossRef] [PubMed]

45. Popper, Z.A.; Fry, S.C. Widespread occurrence of a covalent linkage between xyloglucan and acidic polysaccharides in suspensioncultured angiosperm cells. Ann. Bot. 2005, 96, 9199. [CrossRef]

46. Moore, J.; Farrant, J.; Driouich, A. A role for pectin-associated arabinans in maintaining the flexibility of the plant cell wall during water deficit stress. Plant Signal. Behav. 2008, 3, 102-104. [CrossRef] [PubMed]

47. Zhao, C.; Zayed, O.; Zeng, F.; Liu, C.; Zhang, L.; Zhu, P.; Hsu, C.C.; Tuncil, Y.E.; Tao, W.A.; Carpita, N.C.; et al. Arabinose biosynthesis is critical for salt stress tolerance in Arabidopsis. New Phytol. 2019, 224, 274-290. [CrossRef] [PubMed]

48. Nguema-Ona, E.; Vicré-Gibouin, M.; Cannesan, M.A.; Driouich, A. Arabinogalactan proteins in root-microbe interactions. Trends Plant Sci. 2013, 18, 1360-1385. [CrossRef] 
49. Mareri, L.; Romi, M.; Cai, G. Arabinogalactan proteins: Actors or spectators during abiotic and biotic stress in plants? Plant Biosyst. Int. J. Deal. Asp. Plant Biol. 2019, 153, 173-185. [CrossRef]

50. Nguema-Ona, E.; Moore, J.P.; Fagerström, A.D.; Fangel, J.U.; Willats, W.G.T.; Hugo, A.; Vivier, M.A. Overexpression of the grapevine PGIP1 in tobacco results in compositional changes in the leaf arabinoxyloglucan network in the absence of fungal infection. BMC Plant Biol. 2013, 13, 46. [CrossRef]

51. Li, Y.L.; Yu, Y.K.; Zhu, K.M.; Ding, L.-N.; Wang, Z.; Yang, Y.-H.; Cao, J.; Xu, L.-Z.; Li, Y.-M.; Tan, X.-L. Down-regulation of MANNANASE7 gene in Brassica napus L. enhances silique dehiscence-resistance. Plant Cell Rep. 2021, 40, 361-374. [CrossRef] [PubMed]

52. Lahlali, R.; Kumar, S.; Wang, L.; Forseille, L.; Sylvain, N.; Korbas, M.; Muir, D.; Swerhone, G.; Lawrence, J.R.; Fobert, P.R.; et al. Cell wall biomolecular composition plays a potential role in the host type ii resistance to Fusarium head blight in wheat. Front. Microbiol. 2016, 7, 910. [CrossRef]

53. Kacurakova, M.; Capek, P.; Sasinkova, V.; Wellner, N.; Ebringerova, A. FT-IR study of plant cell wall model compound: Pectic polysaccharides and hemicelluloses. Carbohydr. Polym. 2000, 43, 195-203. [CrossRef]

54. Cosgrove, D. Microbial expansins. Annu. Rev. Microbiol. 2017, 71, 479-497. [CrossRef] [PubMed] 